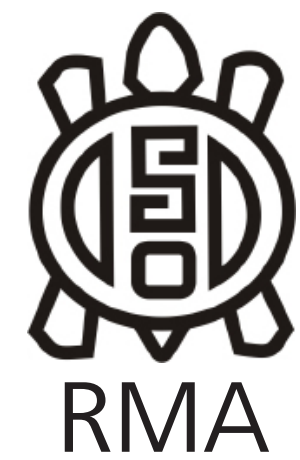

Dossier

\section{El problema del registro arqueológico anterior al 1000 AP y la cerámica incisa/ grabada en la zona del río Salado (llanura de Santiago del Estero, Argentina)}

\author{
The problem of the archaeological record before 1000 AP and the \\ ceramic incised/engraved in the area of the Salado River (plain of \\ Santiago del Estero, Argentina)
}

Constanza Taboada*

${ }^{*}$ CONICET, Instituto de Arqueología y Museo, Facultad de Ciencias Naturales e IML, Universidad Nacional de Tucumán, Argentina. E-mail: constanzataboada@gmail.com

\begin{abstract}
Resumen
Este trabajo busca visibilizar y problematizar la ausencia o eventualidad de registros atribuibles al primer milenio conocidos para la zona del río Salado (Santiago del Estero, Argentina), así como los problemas que surgen de las clasificaciones cerámicas relacionadas con el tema. Para ello reevalúa los datos disponibles en relación a sus modos de construcción a lo largo de la historia de la arqueología local. Como resultado se hace evidente la homogeneización que ha actuado sobre la variabilidad de cerámicas incisas y grabadas locales, así como los problemas y potencialidades de atribución contextual y cronológica. El análisis muestra una ocupación humana clara a partir del límite entre el primer y segundo milenio y la posibilidad de una instalación previa asociada a montículos, modalidad no registrada por entonces en la zona del río Dulce. Finalmente se postulan algunas hipótesis de trabajo para guiar nuevas observaciones. Las mismas plantean que una suma de factores de distinta índole (modos de producción de datos, factores formadores de sitios, dinámica ambiental, modos de vida, etc.) pudieron actuar generando una muy baja visibilidad y registro de sitios y evidencias previos al 1000 AP en una zona donde la instalación pudo -por razones ambientales y culturales a profundizar- ser de baja densidad por entonces.
\end{abstract}

Palabras clave: montículos; período Temprano; historia de la arqueología; fechados; alfarería.

\begin{abstract}
This paper seeks to make visible and problematize the eventuality of archaeological records attributable to the first millennium known for the Salado River area (Santiago del Estero, Argentina), as well as the problems that arise from the ceramic classifications related to it. For this, it reevaluates data available and the ways of building them throughout the history of local archeology. As a result, the homogenization that has acted on the variability of incised ceramics or local engravings is evident, as well as the problems and potentials of contextual and chronological attribution. The analysis shows a clear installation for the boundary between the first and second millennium and the possibility of a previous installation already associated with mounds and not registered at that time in the area of the Dulce River. Finally, some working hypotheses are postulated to guide new observations. They suggest that a sum of factors of different kinds (data generation modes, site-forming factors, environmental dynamics, lifestyles, etc.) could act generating a very low visibility and registration of sites / evidence prior to $1000 \mathrm{BP}$ in an area where the installation could - for environmental and cultural reasons to deepen - be of low density.
\end{abstract}

Keywords: mounds; early period; history of archeology; radiocarbon dates; pottery.

En memoria de Margarita Silva (post scriptum)

\section{Introducción, planteo del problema y metodología}

Este trabajo busca visibilizar y problematizar la ausencia o eventualidad de registros atribuibles al primer milenio de la era cristiana conocidos hasta ahora en torno al río
Salado (Santiago del Estero, Argentina), así como los problemas que surgen de las clasificaciones cerámicas relacionadas con el tema. La región de estudio abarca el centro de la llanura de Santiago del Estero -en adelante SdE-, cubriendo parte del chaco santiagueño y del este de la mesopotamia local (Fig. 1). El fechado más antiguo para la zona fue obtenido en el sitio El Veinte y se remonta a 


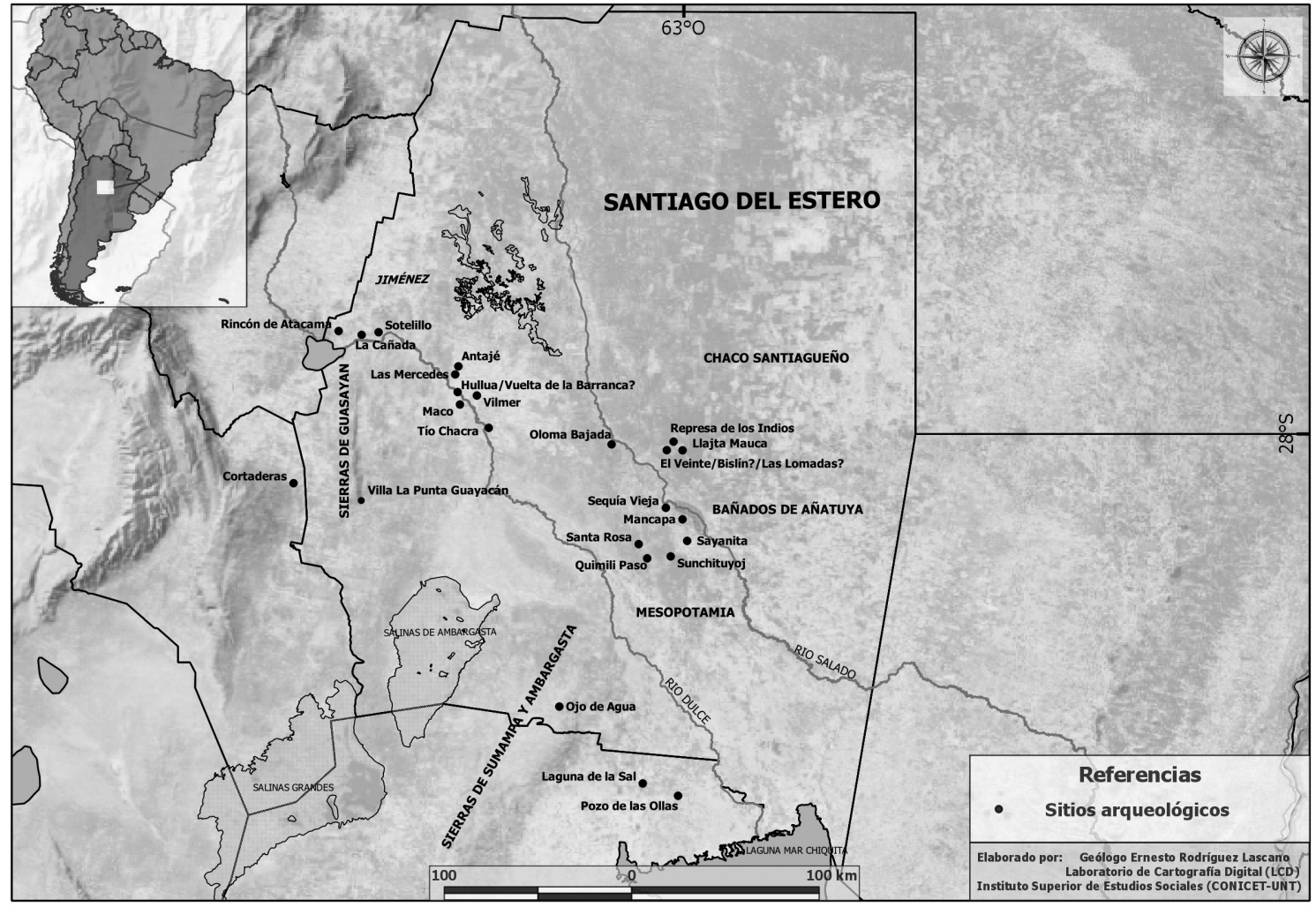

Figura 1. Mapa con los sitios mencionados en el texto. Realizado por Ernesto Rodríguez Lascano (ISES-CONICET) en base a Reichlen (1940), Imbelloni (1940), Bleiler (1948), Gómez (1966), (2009), Lorandi (1974), Oliva (1947), Togo (2004), Taboada (2019) y mapas catastrales.

Figure 1. Map with the sites mentioned in the text. Designed by Ernesto Rodriguez Lascano (ISES-CONICET) based on Reichlen (1940), Imbelloni (1940), Bleiler (1948), Gómez (1966), (2009), Lorandi (1974), Oliva (1947), Togo (2004), Taboada (2019) and cadastral maps.

inicios del segundo milenio; otro del sitio Quimili Paso -ya en la mesopotamia sudoeste- remite a fines del primer milenio (Lorandi 1974). A la vez, los trabajos en el área han ofrecido escasos y discutibles indicios considerados de un Período Temprano (Bleiler 1948) o Formativo Inferior (Gómez 2009), o caracterizados como Cultura o cerámica Las Mercedes, referente tradicional regional de dichos períodos (González 1977; Gramajo 1978; Reichlen 1940) (Fig. 2). La situación contrasta con la estudiada en la cuenca alta y media-alta del río Dulce y Sierras de Guasayán, para donde existen dataciones asociadas a ocupaciones alfareras a partir de, al menos, mediados del primer milenio (Togo 2004, 2007).

En vistas a ponderar las causas de esta situación, en este trabajo revisamos y reconsideramos una serie de datos procedentes de investigaciones propias y de las realizadas a lo largo de más de 100 años de arqueología local. Sumamos a ello una metodología que intenta situar y poner en claro los intereses y modos de producción académica y personal de los investigadores vinculados al tema, con el fin de evaluar "ruidos" que originan problemas para la consideración actual de la información, clasificaciones e interpretaciones generadas por ellos. Hasta ahora se han revisado diapositivas y registros inéditos de Ana María Lorandi, parte de las colecciones formadas por Emilio y Duncan Wagner, Olimpia Righetti y Henry Reichlen depositadas en el Centro de Interpretación y Conservación del Patrimonio Cultural de Santiago del Estero (CICPSE) y en el Centro Cultural del Bicentenario de Santiago del Estero (CCB), material del Museo Municipal Rincón de Atacama (Termas de Río Hondo), información del Museo de Antropología de Córdoba donde se resguardan archivos y la colección formada por Jorge Von Hauenschild, y fichas y fotografías de materiales enviados por E. Wagner y H. Reichlen al Museo del Trocadero de Paris (luego Museo del Hombre) y actualmente trasladadas al Museo Quai Branly. Lamentablemente, gran parte del material recuperado por Roque Gómez y donado a la Universidad Nacional de SdE parece haberse perdido por un incendio (Gómez 2009). Además, se reubicó el sitio El Veinte, trabajado por Lorandi en los años 70. Estos datos, y las interpretaciones vertidas en las publicaciones, fueron considerados en articulación con información biográfica y trayectorias de investigación de los distintos autores, a fin de evaluar lógicas e intereses de investigación, fuentes 

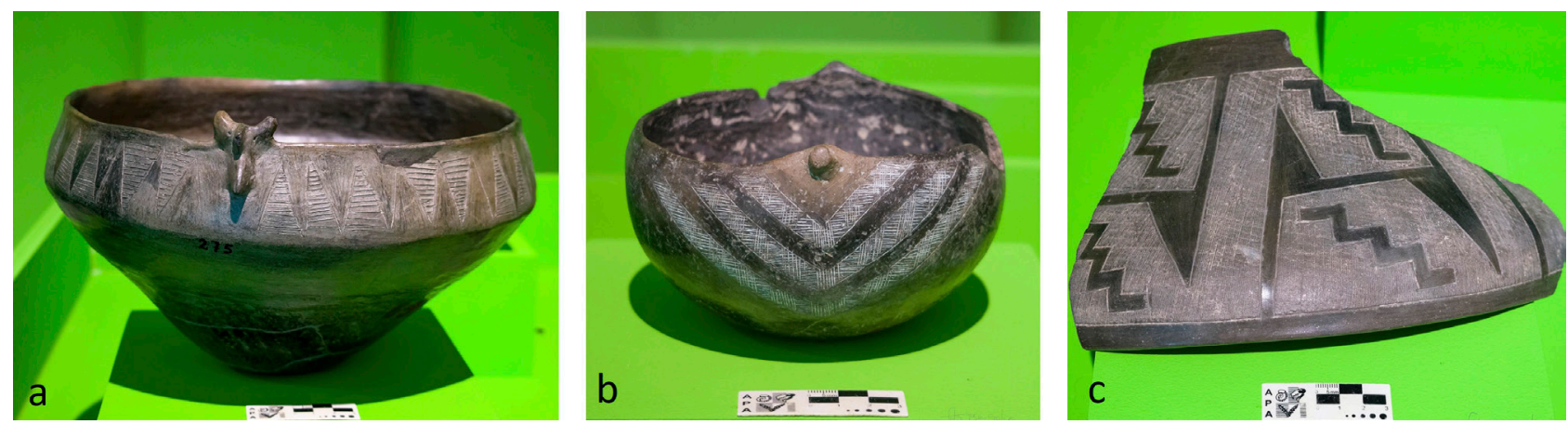

Figura 2. a) Recipiente clasificado como Las Mercedes Gris Grabado en las fichas del Museo Wagner ( $\left.\mathrm{N}^{\circ} 275 / \mathrm{N}^{\circ} \mathrm{B} 569\right)$ y $\sin$ datos de procedencia dentro de SdE. b) Puco clasificado como Las Mercedes Gris Grabado en las fichas del Museo Wagner ( $\mathrm{N}^{\circ} 742 /$ $\left.\mathrm{N}^{\circ} \mathrm{B} 179\right)$ y sin datos de procedencia dentro de SdE. C) Fragmento procedente de Vuelta de La Barranca clasificado en las fichas del Museo Wagner como Las Mercedes Gris Grabado (N 743/ B366). Expuestos en el CCB de SdE. Fotografías: José Galván (CICPSE).

Figure 2. a) Container classified as Las Mercedes Gris Grabado in the Wagner Museum's files ( $N^{\circ} 275 / N^{\circ}$ B569) and without provenience data within SdE. b) Puco (bowl) classified as Las Mercedes Gris Grabado in the Wagner Museum's files ( $N^{\circ} 742 / N^{\circ}$ B179) and without provenience data within SdE. C) Fragment from Vuelta de La Barranca classified in the Wagner Museum files as Las Mercedes Gris Grabado (N 743 / B366). Exhibited at the CCB of SdE. Photographs: José Galván (CICPSE).

utilizadas, criterios y discrepancias en las definiciones de tipos cerámicos y nombres de sitios. Conjuntamente se han revisado clasificaciones, catálogos y descripciones de cerámica documentadas en áreas vecinas, a fin de comparar los registros con los de nuestra zona de estudio y detectar posibles semejanzas que, a futuro, pudieran aportar a evaluar las dinámicas socioculturales implicadas.

Por su parte, si bien el análisis del problema se basa principalmente en los fechados y en los registros cerámicos existentes en sus aspectos estilísticos, este trabajo no es un estudio específico de los mismos ni considera que tales evidencias cobren mayor relevancia que otras. El artículo apunta a hacer una reevaluación de situación y planteo inicial del problema que -en esta instancia- se apoya principalmente en el uso de dichos datos porque sobre ellos se han centrado las propuestas que buscamos revisar, además de ser casi los únicos descriptos. Tampoco pretendemos hacer un estudio sobre el primer milenio para todo SdE. Lo que intentamos es exponer y analizar los datos y discusiones vinculados al tema para la zona en torno al río Salado, en función de poner en limpio el potencial e incertidumbres que conllevan y de clarificar el problema. Un posterior abordaje del mismo requerirá del análisis directo de materiales y situaciones de campo, aplicando marcos teóricos y metodologías que amplíen la consideración de clasificaciones estilísticas ${ }^{1}$ usadas como principal elemento de análisis por los autores previos, que tengan en cuenta el conjunto de evidencias asociadas a cada uno de los contextos que se analizan, que generen fechados y que amplíen las comparaciones con los registros cerámicos de las tierras bajas circundantes, con

\footnotetext{
${ }^{1}$ Algunos autores incorporaron referencias de formas o de pastas, pero como no constituyen los elementos definitorios de sus clasificaciones y planteos se deja su análisis para una segunda instancia de investigación e integración.
}

el fin de articular resultados en modelos que puedan dar cuenta de los procesos socio-históricos ocurridos durante el primer milenio en la zona de estudio y su relación con los de zonas vecinas.

Un primer aspecto en la consideración del problema se refiere a la región que sirvió de marco para los estudios previos. En este sentido, la histórica consideración de una Región Chaco Santiagueña (González 1977) que cubría la mayoría de la provincia -y terminó en la práctica como sinónimo de ella-, o de una arqueología de Santiago del Estero (Gramajo 1978; Wagner y Wagner 1934), estableció un amplio espacio geográfico como marco de investigación que, a pesar de su diversidad natural y cultural (Lorandi 1978; Reichlen 1940; Von Hauenschild 1949), quedó constituido como unidad de análisis (Taboada 2011, 2019)². Esto ha llevado a buscar y a hacer extensivas postulaciones establecidas solo para ciertos sectores o situaciones, y a que entidades culturales y características definidas a su interior se asumieran para toda la provincia. Esto hace mella también en nuestro problema, por cuanto lo que mayoritariamente se sabe del primer milenio se concentra en torno a las Sierras de Guasayán y cuenca alta y media-alta del río Dulce, mientras que su ausencia o eventualidad en otras zonas surge de la comparación con dichos registros y de pensar una manifestación generalizada para todo SdE.

Como adelantamos, el otro gran problema es la definición, identificación y uso dado a los tipos y estilos cerámicos sobre los que se han construido las proposiciones vinculadas al primer milenio. En tanto herramientas metodológicas, las clasificaciones pierden

\footnotetext{
2 Esta unidad de estudio se funda en el marco del desarrollo de la arqueología pionera local y su patrocinio como emblema identitario provincial (Martínez et al. 2011).
} 
su valor descriptivo y de sistematización si son confusas o inciertas $y$, a la vez, se constituyen en un problema si se las esencializa. De ahí nuestro interés en deconstruir las trayectorias y cobertura de las aplicadas a nuestra zona y tema de interés como parte importante para abordar el problema en análisis. En la mayoría de los casos, las descripciones son insuficientes para evaluar lo que un autor consideró dentro de un determinado tipo; en otros son demasiado amplias o incluyen un conjunto heterogéneo de materiales y contextos asociados a ellos, en otros hay superposición de rasgos entre tipos definidos por distintos investigadores. Esto ha generado asunciones, arrastre y transformación de información, ocasionando cierto caos de nombres y tipologías o, por el contrario, generalizaciones que requieren de una revisión para establecer a qué se refería cada autor en su producción original ${ }^{3}$. Desandar estos procesos de construcción de datos y postulaciones es parte de lo que busca este trabajo para definir el problema en cuestión.

\section{Arqueología de la Arqueología. Desandando trayectorias y construcciones de datos}

En 1938, Henry Reichlen y Olimpia Righetti, colaboradores de los hermanos Wagner, llamaron la atención sobre el hallazgo de una cerámica "novedosa" para SdE. Se trataba de una "cerámica negra", "grabada" (Fig. 3) y supuestamente desconocida por las investigaciones previas, aunque un análisis de las colecciones y bibliografía muestra que los Wagner habían visualizado una alfarería negra que podría ser similar. Con base en los descubrimientos de Righetti en el sitio Las Mercedes sobre el Dulce, y de sus propios y más acotados hallazgos en Sayanita al oeste del Salado, Reichlen definió la "Industria Las Mercedes". La caracterizó por una serie de rasgos alfareros -que ampliaremos-y otros elementos asociados (Reichlen 1940). Señaló su asociación a una cerámica tricolor -que Serrano (1958) denominó Cortaderas por el sitio homónimo de Catamarca-, de la cual los Wagner $(1934)^{4}$ habían ilustrado un ejemplar procedente de la mesopotamia santiagueña, dos del Dulce -Vilmer y Maco-, y otro -no señalado por Serrano- procedente de Tío Chacra, también sobre el Dulce, diferenciado por Lorandi (1978) por su carácter figurativo y comparado con la figura draconiforme de las urnas de Ambato, Catamarca $^{5}$ (Figura 2).

\footnotetext{
3 Además, en muchos casos se han usado los términos inciso y grabado de forma indistinta o sin definición de su significado. Por ello, y hasta tanto el material sea sometido a un análisis directo, usaremos la terminología de cada autor. En los casos en que debamos hacer referencias generales usaremos el término inciso para referir cualquier tratamiento de superficie que implique remoción o corrimiento de pasta.

4 Los Wagner (1934) señalan que algunas estaban acompañadas de fragmentos de cerámica negra grabada, que Reichlen (1940) interpreta como indicadores de yacimientos Las Mercedes.

${ }^{5}$ Se han hallado otras piezas Cortaderas en el Dulce superior y medio y en las Sierras de Guasayán (Museo Rincón de Atacama; Gómez 1966, 2009; Togo 2004).
}

Ahora bien, Reichlen (1940) distinguió a aquella cerámica negra y sus contextos de las otras dos industrias que había definido para la región (Averías y Sunchituyoj). Estos tres grandes conjuntos cerámicos, y los materiales asociados a ellos, tomaban como base las dos grandes "Ramas" (A y $B$ respectivamente para Averías y Sunchituyoj) y una tercera apenas vislumbrada (Rama C) de la Civilización Chaco-Santiagueña de los Wagner (1934). Más adelante, Von Hauenschild (1949) daba cuenta de cerámica negra -descripta como incisa- en la cuenca media-alta del Dulce ${ }^{6}$, que clasificó como Cuarta Ola o con Rastros Andinos. Parte de este material, hoy en el Museo de Antropología de Córdoba (Lindskoug 2012; Pautassi et al. 2017), es análogo al posteriormente considerado Las Mercedes por Gómez (1966) (Lorandi 2015). Sobre estas bases y trabajos propios, Gómez (1966) definió la Cultura Las Mercedes, estimando, por cronología cruzada y relativa, que podía haberse desarrollado a partir de mediados del primer milenio. Dentro de esta Cultura diferenció tres tipos cerámicos (Las Mercedes ${ }^{7}$, Antajé ${ }^{8}$ y Cortaderas ${ }^{9}$ ) y subgrupos, que se asociaban entre sí diferencialmente y mostraban distinta distribución espacial

A pesar de esta variabilidad, las postulaciones de Reichlen y Gómez funcionaron como una suerte de homogenización a la hora de considerar el periodo Temprano. Así, la cerámica definida como Las Mercedes, integrada como una Cultura, o resumida al carácter de una alfarería negra/gris y/o incisa/grabada, se constituyó en el referente del Período Temprano de la Región Chaco

\footnotetext{
6 Según Gómez (2009), el sitio Rubia Moreno de Von Hauenschild sería el mismo que el sitio Las Mercedes.

7 Incluye las variantes Gris y Roja, en sus modalidades Lisa o Grabada, y la Pintada Grabada. Las Mercedes Grabada presentaría "guardas geométricas, triángulos, escaleras y espirales...Toda la superficie ha sido grabada en técnica negativa con un rayado o cruzado muy apretado y poco profundo... los dibujos han quedado en su interior sin grabar, lisos y bien pulidos" (Gómez 1966: 12-13). Según el autor, la variante Grabada Pintada sería similar a la Grabada pero con pintura postcocción naranja o rosa que recubre la parte rayada. Sin embargo, las ilustraciones de este tipo (Gómez 1966, 2009) no permiten apreciar la pintura. Uno de estos ejemplos hallado en "Hullua" es casi igual a una pieza del Museo Wagner procedente de "Vuelta de la Barranca"-paraje ubicado a unos $8 \mathrm{~km}$ de la zona de Hullua (o Úlluas) y que quizás podría aludir al mismo sitio- que está catalogada en la ficha del museo como Mercedes Gris Grabado y en la cual tampoco se aprecia pintura en la observación macroscópica (ver Fig. 2).

8 Toma el nombre del sitio homónimo. Es caracterizada por presentar "guardas muy simples" -a diferencia de Las Mercedes Grabada- y por "estar acompañada de otra cerámica gris o roja muy parecida a la cerámica Las Mercedes Lisa, aunque algo más compacta que aquella. La escases de registros grabados es muy notoria" (Gómez 1966:17). Tiene "bordes que presentan dibujos en cruz, zigzag o rayado... La decoración consiste en guardas simples que se reducen a triángulos, rectángulos, rombos o zigzag ubicados alrededor del borde, pero el rayado o zig zag se ha hecho dentro del dibujo, quedando lisa y pulida la superficie restante; este rayado o cruzado es profundo y menos apretado que el Mercedes [Grabado?]" (Gómez 1966:18).

9 A la definición de Serrano (1958), que remitiría a un Cortaderas Polícromo, Gómez (1966) agrega Cortaderas Roja sobre Blanco y Roja sobre Ante. Primero Gómez (1966) dice que Antajé no se asocia a Cortaderas, lo que rectifica después (Gómez 2009).
} 
Santiagueña y SdE (González 1977; Gramajo 1978). Tal fue el caso aun cuando para gran parte de SdE no hay registro de ella y en ciertos sectores se han hallado otras manifestaciones asociables a un Período Temprano, como ser piezas Candelaria hacia el centro y noroeste provincial (Gramajo 1978; Togo 2004; Wagner y Wagner 1934). Por su parte, aquella alfarería negra/gris, incisa/ grabada, solo había sido identificada con certeza en sectores acotados de la Provincia, principalmente en torno al Dulce superior y medio-superior (Gómez 1966, 2009; Von Hauenschild 1949), con registros puntuales o discutibles en uno o unos pocos sitios de la zona del Salado (Bleiler 1948; Reichlen 1940) ${ }^{10}$. Como veremos, entre ellas hay diferencias estilísticas, contextuales, de asociación y distribucionales. Esta diversidad y sus potenciales implicancias han quedado camufladas a la hora de reconocer y analizar la situación en diferentes contextos y sectores de SdE.

De hecho, los Wagner y Reichlen habían identificado una cerámica "grabada" (beige o rojiza), especialmente en los bordes de recipientes (mostrando líneas entrecruzadas, paralelas o sucesión de punteados o muescas) (Wagner y Wagner 1934: Lam XVI-XIX). En ocasiones esta cerámica presenta pintura blanca o amarilla sobre un conjunto de líneas subparalelas o entrecruzadas, incisas o peinadas, contenidas dentro de campos subcirculares dispuestos en el cuerpo de la pieza, pero que difieren de la modalidad usada en las piezas Las Mercedes Grabado Pintado ilustradas por Gómez (1966). Hasta recientemente esta variante no había sido particularmente diferenciada, por lo que para poder referirla la denominaremos Santa Rosa Inciso (y Santa Rosa Inciso Pintado cuando se da además esta característica) por su abundancia en el sitio homónimo de la mesopotamia"1 (Taboada 2019). Aquellos autores consideraron que esta alfarería integraba la Rama B (Wagner y Wagner 1934) y la "Industria Sunchituyoj" (Reichlen 1940) y efectivamente suele hallarse asociada a cerámica Sunchituyoj.

Otro grupo de incisos, que muestran caracteres

\footnotetext{
10 Gramajo (1978) incluye algunos puntos más con presencia de Las Mercedes en SdE, pero no desarrolla en qué basa tal atribución/distribución. Uno de los lugares parece corresponderse con la ubicación del sitio El Veinte/Bislín, sobre el que discutimos en este trabajo la asignación de su cerámica como Las Mercedes. Gómez (2009) señala la presencia de Mercedes Incisa (sic) también en Pozo de las Ollas y Laguna de la Sal (al norte de Córdoba) en base al trabajo de Oliva (1947). Sin embargo, el material ilustrado por Oliva presenta caracteres con marcadas diferencias respecto de los clasificados o ilustrados por Gómez como los diferentes tipos de Las Mercedes. Salvo los bordes con incisiones -señalados por Gómez (1966) para Antajé y que aparecen también en otro tipos incisos-, el material no muestra elementos en común con Las Mercedes. Algunos fragmentos se asemejan a Bislín Inciso y a fragmentos de El Veinte (cfr. Fig. 5). Según las ilustraciones de Oliva, en Pozo de Las Ollas parecen asociarse a material Sunchituyoj pintado, al igual que en el sitio Bislín y El Veinte. Un par de fragmentos podrían ser Averías e indicar una ocupación más tardía.

11 Fragmentos recolectados en El Veinte y considerados como Bislín Inciso (sensu Bleiler 1948) por Lorandi (1974) podrían corresponder a esta variante (por ejemplo, el ilustrado en la Fig. 5a:8).
}

parcialmente compartidos o análogos con dicha cerámica (como los bordes incisos con puntos), pero carente de otros rasgos o no descriptos (como los campos subcirculares rellenos por incisiones y pintados), apenas representados por los Wagner, clasificados también dentro de su Rama B (Wagner y Wagner 1934) y asociados a cerámica Sunchituyoj Fase las Lomas en el sitio El Veinte (Lorandi 1974; Reichlen 1940), fueron aislados por Bleiler (1948) bajo el nombre de Bislín Inciso, tomando el nombre del sitio homónimo del Salado (ver Fig. 4). Bleiler describe esta alfarería configurada por impresiones, incisiones y puntuaciones simples que, en general, encierran el cuello de las vasijas formando filas de cruces, triángulos pendientes punteados, zigzags, rayados e incisiones faciales. Bleiler dice que es "generalmente referida como gris o negra", aunque según Lorandi (2015) (y observación de fragmentos recolectados personalmente en El Veinte -quizás el mismo sitio que Bislín según Lorandi 1974), es rojiza o amarillenta y solo eventualmente puede ser gris por mala cocción (recordemos que Bennett, Bleiler y Sommer basaron su propuesta en material publicado y los ejemplos ilustrados por los Wagner están en blanco y negro) (ver Fig. 5). El tipo presenta algunos rasgos semejantes al definido como Córdoba Inciso (Serrano 1958) (ver Fig. 3); lamentablemente Serrano no hace mención al mismo como para evaluar su posible sinonimia o diferencias ${ }^{12}$. Una característica distintiva de ambos tipos respecto de los grupos considerados Las Mercedes (en los que para el relleno de guardas semejantes se ha ilustrado el uso de rayas; ver ejemplos en Gómez 1966 y Togo 2004) es el rellenado y bordeado de bandas por medio de puntos (sin excluir el uso del rayado). En base a algunas consideraciones de Palavecino (1934, en Bleiler 1948) y Casanova (1942, en Bleiler 1948), que en la zona del Dulce habían registrado cerámica gris por debajo de otra policroma, Bleiler (1948) ubicó al Bislín Inciso en un Período Temprano. Por su parte, Bleiler señala que los fragmentos reportados por Reichlen para Jiménez y Ojo de Agua son semejantes a la cerámica Huiliche Monocromo (luego denominada Ciénaga y Aguada) pero con decoración menos elaborada. Los mismos habían sido descriptos por Reichlen como "piezas muy bellas de cerámica grabada... decoradas con motivos sensiblemente diferentes de los... de Sayanita y Las Mercedes" (Reichlen 1940: 202) (ver Fig. 3a), evidenciando una vez más la variabilidad existente entre los incisos regionales. Gómez (2009) señala que podrían ser del tipo Las Mercedes Inciso (sic) (¿Mercedes Grabada?). Por su parte, Gómez (1966) indicó que el tipo Antajé se hallaba también en el sitio Bislín y la escasa resolución del texto lleva a entender que Gómez integraba al Bislín Inciso dentro de la Cultura Las Mercedes (Lorandi 2015). Como vimos, la descripción de Antajé parece agrupar a un conjunto bastante heterogéneo, en el que

\footnotetext{
12 Quizás el tipo Bislín Inciso de Bleiler incluía -sin detallarlo- lo considerado Córdoba Inciso y Santa Rosa Inciso, ya que el autor no los diferencia y hay fragmentos asignables a estos tipos ilustrados por los Wagner que Bleiler debió ver.
} 
podría caber dicho tipo. Comparte con él, y también con el Santa Rosa Inciso, la referencia de incisiones en los bordes, pero el resto de la descripción difiere y no da cuenta de rasgos específicos como las guardas y triángulos rellenos de puntos o rodeados externamente por ellos que caracterizan también al Córdoba Inciso, ni de los campos con incisiones y pintura encima como el Santa Rosa Inciso Pintado. En un trabajo posterior, Gómez (2009) señala más específicamente que en el sitio Bislín los Wagner ilustran un fragmento Antajé. Efectivamente, hay un fragmento del sitio Bislín ilustrado por los Wagner (1934) (ver Fig. 4:2) que muestra una guarda en zigzag rellena de líneas paralelas perpendiculares a la banda que es consistente con la descripción (Gómez 1966) y con una ilustración (Gómez 2009) de Antajé (y con fragmentos de Sayanita de Reichlen; ver Fig. 3a). En base a ello entendemos que Gómez -que no trabajó personalmente el sitio Bislín- no incluye como parte de Antajé a los demás fragmentos incisos ilustrados por los Wagner en la misma figura, que corresponden al Bislín Inciso de Bleiler (de todos modos, es incomprensible que Gómez, quien cita el trabajo de Bleiler (1948), no explicite cómo considera al tipo Bislín Inciso). Lorandi (2015) considera que Bislín Inciso acompaña contextos de la Fase Las Lomas (con cerámica Sunchituyoj) más que contextos asociados a Las Mercedes. Finalmente cabe señalar que el grupo Inciso 1 de Lorandi (1974), diferenciado de Las Mercedes y comparado por su similitud temática con los tipos de Córdoba y del Litoral, comprendería los distintos incisos recién descriptos.

\section{Los fechados radiocarbónicos}

Hasta el momento se han publicado 42 fechados para $\mathrm{SdE}$. El ordenamiento de sus calibraciones muestra una distribución espacial creciente de oeste a este: los más antiguos se ubican en las Sierras de Guasayán y siguen en orden de aparición los del Dulce superior, mesopotamia y Salado. Hasta ahora, los más antiguos fueron obtenidos por Togo para contextos asociados a cerámica considerada Las Mercedes (Togo 2007) (que incluyen también cerámica Cortaderas, Togo 2004) en un sitio de las Sierras de Guasayán (Villa La Punta Guayacán) y en tres sitios sobre el Dulce superior (Rincón de Atacama, Sotelillo y La Cañada). Son 13 dataciones que cubren un rango

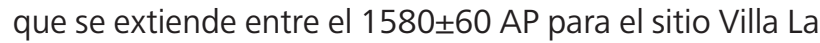
Punta Guayacán y $1060 \pm 70$ AP para el sitio La Cañada, con un fechado más alejado de $700 \pm 70$ AP para el sitio La Cañada asociado también a cerámica considerada Las Mercedes y que el autor remarca como evidencia de su perduración hasta entonces (Togo 2007). Para este sitio, Togo (2004:694) ilustra también material en el que vemos semejanzas estilísticas con la cerámica Aguada Portezuelo, pero no hallamos referencias de su situación de asociación estratigráfica o contextual respecto de los fechados ni de los otros tipos cerámicos. Según las descripciones, ninguno de los sitios mencionados es de tipo monticular -común, en cambio, en plena llanura santiagueña- y carecen de cerámica Sunchituyoj o Averías. En dicha zona se han obtenido, además, 10 fechados para momentos posteriores relacionados a contextos sin cerámica Las Mercedes y asociados a Sunchituyoj y/o Averías (Del Papa y de Santis 2015; Togo 2004).

Para el área del Salado se cuenta con 13 dataciones radiocarbónicas realizadas en 4 sitios (El Veinte y Oloma Bajada en la zona del Chaco Santiagueño, y Sequia Vieja y Mancapa en la de los Bañados de Añatuya sobre la vera oeste del Salado) con características diversas entre sí. A ellos se suman 6 fechados obtenidos en el sitio Quimili Paso en la mesopotamia oeste. Las primeras de estas dataciones fueron obtenidas por Lorandi (compendio en Lorandi 2015) en la década del 70 en los sitios El Veinte, Quimili Paso y Oloma Bajada; las restantes fueron obtenidas por nosotros para materiales de Sequía Vieja y Mancapa (Taboada 2014, 2016, 2019). En su conjunto cubren un lapso que se abre con el fechado más antiguo de $1140 \pm 60$ AP para Quimili Paso en la mesopotamia (Lorandi 1974) y llega a $310 \pm 40$ AP para Mancapa al oeste del Salado (Taboada 2014). Para la vera este del Salado, la datación más antigua es de $950 \pm 90$ AP obtenida en El Veinte (Lorandi et al. 1977). Todos estos fechados se asocian a sitios de montículos y, según el sitio y caso, a cerámica Sunchituyoj, Negro sobre Rojo Brillante y/o Averías (sensu Lorandi 1974). Por ahora solo en El Veinte y en Quimili Paso hay registro de cerámica incisa, compatible con Santa Rosa Inciso y Córdoba Inciso en ambos sitios y también con Bislín Inciso en El Veinte (según observación de diapositivas de Lorandi, referencias bibliográficas de la autora y muestreo personal) y asociada a cerámica Sunchituyoj (Lorandi 1974, 1977). Para ninguno se ha descripto o ilustrado material análogo a Las Mercedes Grabada ni a los otros tipos definidos por Gómez para la Cultura Las Mercedes (salvo lo planteado sobre el posible fragmento tipo Antajé para el sitio Bislín, probable El Veinte). Las dataciones más antiguas de Quimili Paso y El Veinte son anteriores o semejantes a los fechados más tardíos obtenidos en el sitio La Cañada sobre el Dulce que, según el registro de Togo (2007), estarían asociados a cerámica Las Mercedes.

\section{La situación en torno al río Salado}

Presentamos ahora los pocos contextos conocidos para la zona del Salado que cuentan con materiales o fechados próximos al primer milenio o que fueron considerados del Período Temprano: Sayanita, Bislín y El Veinte.

Sayanita. Es un sitio consignado por Reichlen (1940), un autor de mirada cuidadosa por lo que sus observaciones pueden ser tomadas en consideración (Martínez et al. 2011). El sitio se ubica en la mesopotamia hacia el Salado, unos $20 \mathrm{~km}$ al sur de Icaño. La visita de Reichlen fue motivada por la referencia del hallazgo "de piezas de cerámica de un tipo absolutamente nuevo... fragmentos de pequeñas vasijas de cerámica gris o negra grabada" 
Figura 3. Fragmentos cerámicos recuperados por Reichlen. a) 1. Procede de Jiménez; 2, 3 y 4 proceden de Sayanita. b) Fragmentos cerámicos tipo Córdoba Inciso procedentes de Córdoba; a y b fueron publicados por Serrano (1958), en blanco y negro y sin escala en el original. c) Pieza de Sayanita catalogada en las fichas del Museo Wagner ( $N^{\circ}$ 914/ N¹66/10) como Las Mercedes Inciso, muestra más bien semejanzas estilísticas con Córdoba Inciso y Bislín Inciso. Depositada en el CICPSE. Fotografía: José Galván (CICPSE).

Figure 3. Ceramic fragments recovered by Reichlen. a) 1. Comes from Jiménez; 2, 3 and 4 come from Sayanita. b) Córdoba-Inciso type ceramic fragments from Córdoba; $\mathrm{a}$ and $\mathrm{b}$ were published by Serrano (1958), in black and white and without scale in the original. c) Vessel by Sayanita cataloged in the files of the Wagner Museum ( $N^{\circ} 914$ / N 166/10) as Las Mercedes Inciso, it shows rather stylistic similarities with Córdoba Inciso and Bislin Inciso. Stored at the CICPSE. Photography: José Galván (CICPSE).
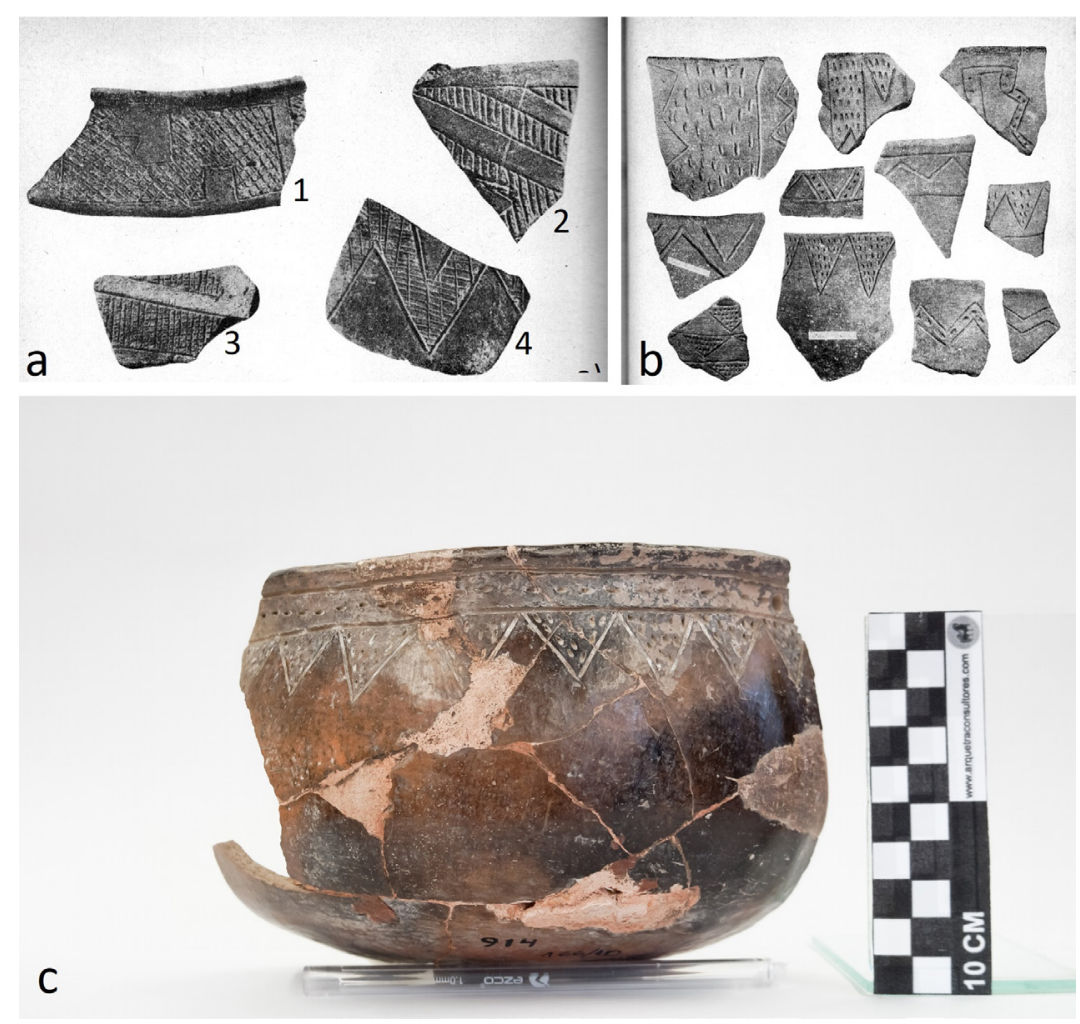

(Reichlen 1940, cursivas nuestras). Según Reichlen, la zona estaba "arrasada" por erosión fluvial, sedimentación y acción del ganado, lo que estima podía ser la causa por la que los montículos apenas podían reconocerse y los materiales en superficie fueran escasos, pequeños y dispersos. Transcribimos in extenso lo que refiere sobre la cerámica porque su descripción es un punto crucial para avanzar en dilucidar la situación. Dice Reichlen:

"La mayor parte de los fragmentos de cerámica no difieren de los de Sunchituyoj. Las cerámicas beiges, lisas y delgadas, de bordes más gruesos marcados con rasgos de puntos, y decoradas con motivos grabados característicos de este yacimiento [Sunchituyoj] son las más abundantes. Al lado de éstas, aparecen fragmentos y vasijas de cerámica grisácea o negra de superficie exterior grabada [Fig. 3.a: 2, 3 y 4]... así como otras con superficie exterior lisa, de color ocre o beige -color natural de la alfarería- pero con la superficie interna revestida enteramente de color negro sobre la cual aparecen motivos muy borrados y difícilmente discernibles de pintura blanca o crema. Una tercera categoría de cerámica acompaña estas vasijas. Se trata de una cerámica con paredes más gruesas, que tienen en el interior rastros de una capa de pintura negra, uniforme y está recubierta exteriormente de un engobe anaranjado sobre el cual algunos motivos están pintados en negro y en blanco" (Reichlen 1940:199).
Y concluye luego:

"... creo poder afirmar que ese yacimiento arqueológico comprende, por una parte, túmulos que procuran una industria del tipo de Sunchituyoj $y$, por otra parte, túmulos que contienen cerámica negra grabada, que acompaña la cerámica de superficie interior pintada en negro y la de engobe anaranjado... Parece entonces que ese mismo sitio de Sayanita ha sido ocupado sucesiva o simultáneamente -el problema de la cronología no ha sido resueltopor dos pueblos o más bien por dos parcialidades de un mismo pueblo... Los descubrimientos hechos en Sayanita muestran así la necesidad de establecer para Santiago del Estero un tercer tipo de civilización que yo llamaría... Las Mercedes... los resultados de mis investigaciones en Sayanita han sido singularmente confirmados algunos meses más tarde por los magníficos descubrimientos hechos en Las Mercedes por la Srta. Olimpia Righetti" (Reichlen 1940:199-200).

Muy poco más se sabe de este sitio, no hay fechados y no tenemos datos sobre materiales que no sean los cerámicos. Aun así, el análisis de fotos y dibujos de los mismos permite avanzar algunas proposiciones. En una primera instancia Gómez (1966) señaló que la cerámica grabada de los sitios Sayanita y Las Mercedes correspondía a su tipo Las Mercedes Grabado; posteriormente se corrige y considera a ambas como Antajé (Gómez 2009). La confrontación con algunas piezas de pasta gris del 


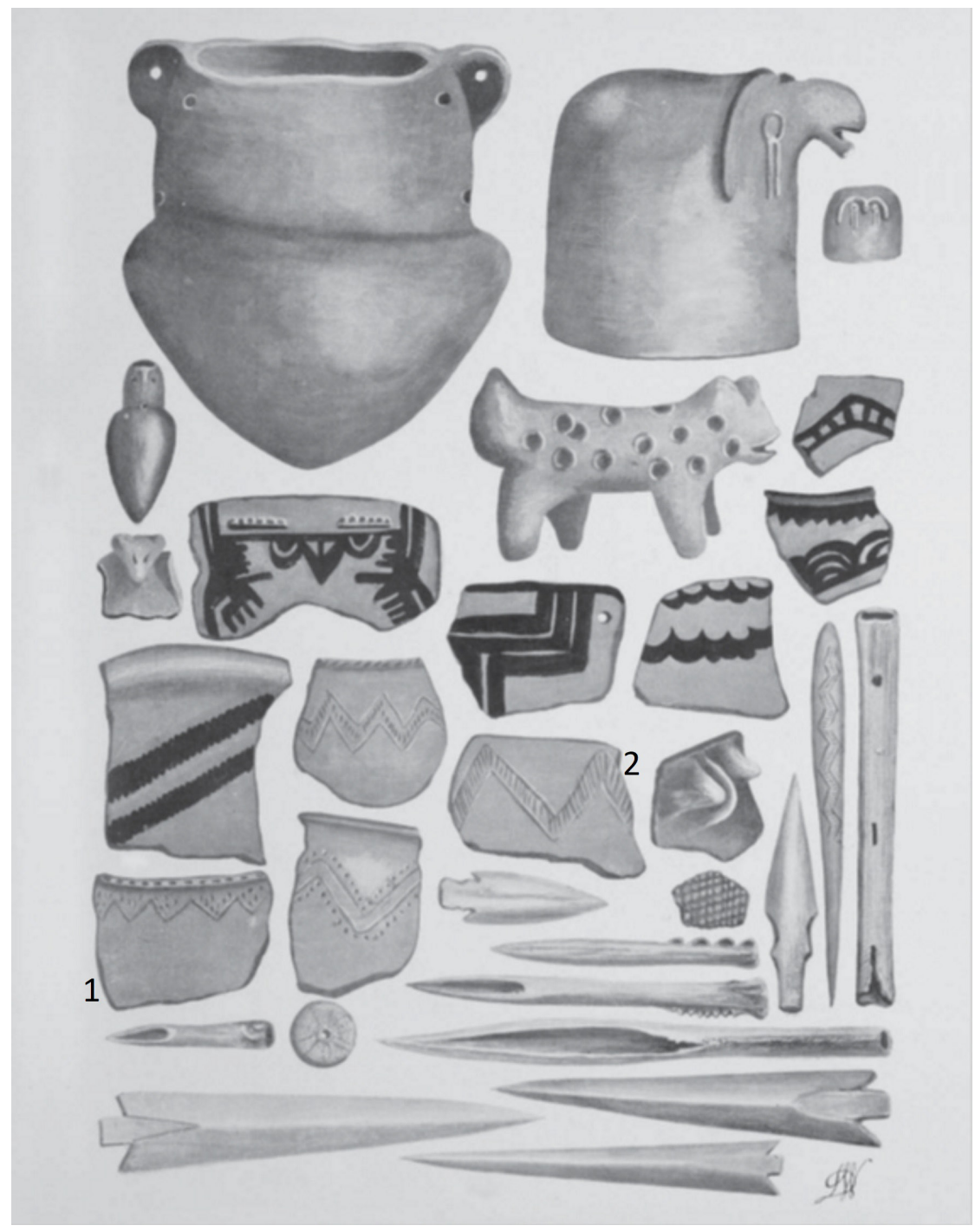

Figura 4. Material procedente del sitio Bislín (todos los objetos salvo las tres puntas de proyectil de abajo). Los fragmentos incisos son los considerados Bislín Inciso por Bleiler (1948). El fragmento 1 podría ser clasificado como Córdoba Inciso (sensu Serrano 1958). El fragmento 2 podría ser el que llevó a Gómez (1966, 2009) a considerar la presencia de Las Mercedes Antajé en el sitio. Los pintados corresponden a Sunchituyoj. Tomado de Wagner y Wagner (1934).

Figure 4. Material from the Bislín site (all objects except the three projectile points below). The incised fragments are those considered Bislin Incised by Bleiler (1948). Fragment 1 could be classified as Córdoba Inciso (sensu Serrano 1958). Fragment 2 could be the one that led Gómez (1966, 2009) to consider the presence of Las Mercedes Antajé at the site. The painted ones correspond to Sunchituyoj. Taken from Wagner and Wagner (1934).

Finalmente, nuestra revisión mostró el registro para Sayanita de alfarería con triángulos rellenos de puntos semejante al tipo Córdoba Inciso (Fig. 3b): una pieza negra amarronada depositada en el CICPSE (Fig. 3c) y un fragmento de pasta roja enviado por Reichlen a París (Museo Quai Branly, $\mathrm{N}^{\circ}$ de Inventario 71.1940.3.256).

CICPSE procedentes del sitio Las Mercedes muestran en común con algunos de los fragmentos recolectados por Reichlen, y con el tipo Antajé de Gómez, el tratamiento en positivo y el relleno de campos con líneas entrecruzadas. La comparación con imágenes presentadas por Togo (2004) evidencia semejanzas también con patrones de representación registrados en los sitios La Cañada, Sotelillo y Villa la Punta Guayacán, sitios con cerámica considerada Las Mercedes y que a su vez aportaron material Cortaderas. Por su parte, la cerámica descripta por Reichlen como de engobe anaranjado con dibujos negros y blancos -presente también en el sitio Las Mercedes- quizás podría ser del tipo Cortaderas (no contamos con imágenes ni con el material para resolver esta posibilidad). Lorandi (1977) muestra dos dibujos en blanco y negro de fragmentos pintados (descriptos como negro y rojo sobre ante, una combinación diferente a la de los pintados referidos por Reichlen) de Sayanita de la ceramoteca del Museo Wagner, que considera no son típicos de Las Mercedes ni de la Fase Las Lomas. Ve allí elementos de representación comunes a Aguada ${ }^{13}$.

\footnotetext{
${ }^{13}$ Lamentablemente no hay datos sobre qué asociación presentarían
}

Tenemos entonces que en Sayanita se halló: cerámica negra grabada (considerable Mercedes Antajé), engobada en naranja con motivos en negro y blanco (¿Cortaderas?), beiges, rojizas y marrones con bordes y cuerpo incisos (asimilables a Córdoba Inciso y no sabemos si también a Bislín Inciso y/o Santa Rosa Inciso), Sunchituyoj, y otras pintadas con posibles semejanzas con cerámica Aguada. Reichlen tiene la certeza de que, al menos la cerámica negra grabada y la de engobe naranja, por un lado, y la Sunchituyoj y los otros incisos por otro, se asocian entre sí y a montículos diferentes respectivamente. Por su parte, los fragmentos que Lorandi ve con rasgos similares a Aguada parecen compartir la coloración y ciertos motivos con los materiales del sitio La Cañada que comparamos con Aguada Portezuelo, pero sería necesario verlos en

en relación a los otros materiales. Resulta por ahora un enigma saber quién recuperó estos fragmentos $y$, en base a ello, saber si efectivamente se trata del mismo sitio. A pesar de que Reichlen señala la novedad del sitio y de que Emilio Wagner lo envía a explorarlo, encontramos que en el Museo Quai Branly hay un par de fragmentos negros grabados ( $N^{\circ}$ de Inventario 71.1910.13.823) de un sitio Sayanita enviados por Emilio Wagner anteriormente (en 1910 cuando recién iniciaba sus investigaciones) y en los censos del CICPSE hay registro de material de un sitio denominado Sayanita que aún no hemos visto. 
Tabla 1. Fechados radiocabónicos obtenidos en el sitio El Veinte (Lorandi et al. 1977).

Table 1. Radiocarbon dates from the El Veinte site (Lorandi et al. 1977).

\begin{tabular}{|l|l|l|l|}
\hline Código & Procedencia & Fecha & Cal 1 sigma \\
\hline GIF-3365 & Montículo B5 nivel 3 & $690 \pm 90$ & AD 1286: cal AD 1394 \\
\hline GIF-3366 & Montículo B4 capa 3 & $720 \pm 90$ & AD 1273: cal AD 1392 \\
\hline GIF-3367 & Montículo 05 capa 3 & $950 \pm 90$ & AD 1042: cal AD 1205 \\
\hline
\end{tabular}

directo pues los de Lorandi son dibujos.

Bislín: a este sitio se lo conoce por los materiales publicados por los hermanos Wagner (1934), pero no hay descripciones del mismo. Kraglievich y Rusconi (1934) dicen que se encuentra 2 leguas al Noroeste del $\mathrm{km}$ 511 (F.C.C.N.A), y un mapa de E. Wagner publicado por Imbelloni (1940) lo ubica en la margen este del Salado. Lorandi (1974) considera que podría ser el mismo que El Veinte, pero posteriormente la autora (Lorandi 1977) vincula a El Veinte con el sitio Las Lomadas de los Wagner, ubicado también en las proximidades (Reichlen 1940). Si fuera El Veinte se trata de un sitio de montículos. Sino, de todos modos, es casi seguro que estuviera constituido por montículos, ya que los Wagner señalan que esta es una característica de su Rama B, la cual es ilustrada principalmente por materiales procedente del sitio Bislín (Wagner y Wagner 1934) (Fig. 4). Además, todos los sitios hasta ahora descriptos en la bibliografía de la zona y reconocidos por nosotros en la misma se caracterizan por la instalación asociada a montículos (Taboada 2019).

De este sitio toma su nombre la cerámica que Bleiler (1948) aisló como Bislín Inciso. Como ya dijimos, de la alfarería ilustrada por los Wagner (1934) para el sitio solo un fragmento presenta semejanzas estilísticas con el tipo Antajé de Gómez. Se trata del que muestra una banda en zigzag rellena con rayas, mientras que el resto muestra punteados incisos. No sabemos su color. Los autores también ilustran cerámica Sunchituyoj (Fase Las Lomas sensu Lorandi 1977); no se ha reportado Averías. El sitio dio cuenta, además, de vasijas y urnas con apéndices troncocónicos y zoomorfos, al menos una "campana" de cerámica, figurinas zoomorfas, puntas de proyectil y otro instrumental de hueso y torteros (Wagner y Wagner 1934; Flores et al. 2019) (Fig. 4). En general, estos últimos no presentan decoración o, en el caso ilustrado por los Wagner, esta es diferente a las más típicas que se ven en los torteros tardíos (Taboada et al. 2018). Kraglievich y Rusconi (1934) identificaron restos de Dolichotis magellanica, Myocastor coypus bonariensis, Cariama cristata, Tupinambis teguixin. Todo el conjunto de materiales es coherente con lo registrado en el sitio El Veinte, sólo que Lorandi no registró torteros en sus trabajos $^{14}$. No hay fechados para el sitio, salvo que sea el mismo que El Veinte.

\footnotetext{
${ }^{14}$ Estos ejemplos muestran el posible desarrollo de textilería en la zona y época, hasta ahora incierta por la ausencia de registro de torteros en las excavaciones de El Veinte (Lorandi 1978; Taboada et al. 2018).
}

El Veinte: es un sitio de montículos trabajado por Lorandi. Se localiza en el paraje El Veinte, al este del Salado. Como dijimos, la autora plantea primero que podría ser el mismo que el sitio Bislín de los Wagner (Lorandi 1974), luego señala su posible correspondencia con el vecino sitio de Las Lomadas trabajado por los mismos autores (Lorandi 1977). El material y la ubicación general son coherentes con ambos. Fue el último de los sitios excavados por Lorandi en SdE (Taboada 2017). Es el sitio tipo de la Fase Las Lomas, la más temprana de la secuencia de la autora (Lorandi 1977) para su Tradición Chaco Santiagueña (en la que no incluye a la Cultura Las Mercedes definida por Gómez). El análisis de los montículos daría cuenta de espacios domésticos poco formalizados, con pisos discontinuos alterados por la inserción de fogones y "hornos" y mediados por capas esteriles (Lorandi 1977, 2015; Taboada 2016). Creemos que esta estructura podría estar dando cuenta de ciclos de ocupación asociados a movilidad residencial (Taboada 2016). El reducido tamaño del sitio (4 hileras con 14 montículos conservados, Lorandi 2015) podría indicar comunidades pequeñas (Taboada 2019). La presencia de materias alóctonas, como artefactos líticos y una campanita de metal (Lorandi 2015), evidencia algún modo de obtención de recursos del oeste provincial. Las poblaciones de El Veinte habrían llevado un modo de vida asociado a la caza y pesca de gran diversidad de animales terrestres, aéreos y acuáticos, y se supone que también hubo recolección de vegetales silvestres, con posibilidad de horticultura de maíz (Cione et al. 1979). Esto se habría dado en el marco de un ambiente más húmedo que el actual y el precedente (Cione et al. 1979; Del Papa 2012), acorde al Cálido Medieval, estimado hacia la misma época -o desde un poco antes- que las dataciones obtenidas en El Veinte (Iriondo 2006; Taboada 2019). Tres fechados ubican su ocupación desde, al menos, inicios del segundo milenio (Tabla 1). Si bien las muestras datadas corresponden a tres montículos diferentes, la autora señala que "el análisis de los materiales indica que El Veinte conforma una sola unidad contextual y cronológica" (Lorandi 2015:119).

Como características cerámicas distintivas del sitio, Lorandi $(1977,2015)$ señala que son frecuentes los tipos incisos similares a los ilustrados por Wagner para el sitio Bislín. Una revisión actual de diapositivas inéditas de la autora y de materiales recientemente recolectados en el sitio ratifica esta similitud, además de mostrar la presencia de otros tipos cerámicos (Fig. 5). Lorandi dice que estos incisos "generalmente son de color rojizoamarillento, pero los hay grises por la mala cocción, e incluso algunos de pasta rosa-violácea bastante 


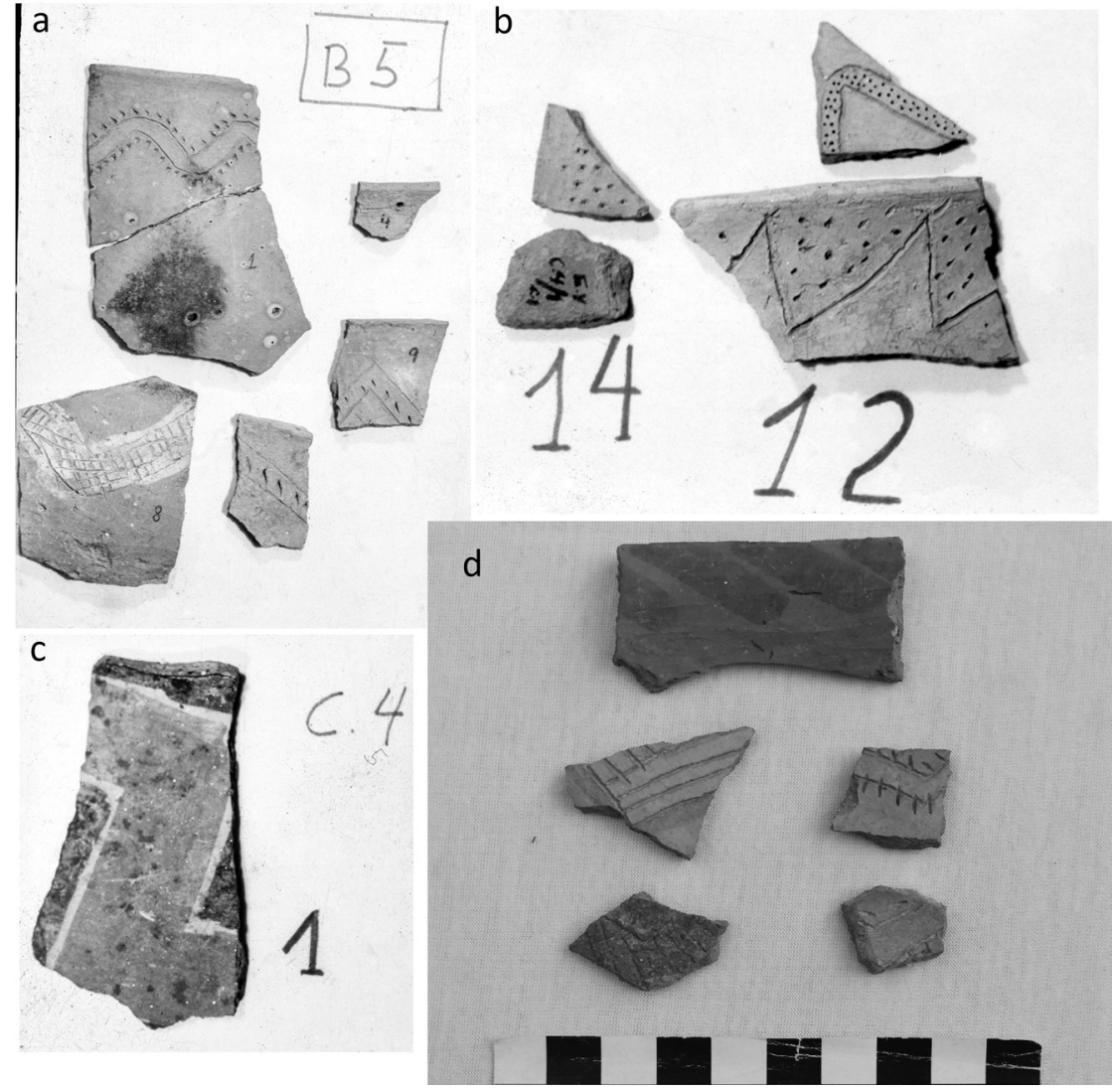

Figura 5. a y b) Material recuperado en El Veinte por A. M. Lorandi. Diapositivas inéditas en blanco y negro de la autora, no tienen escala y las letras y números manuscritos son referencias originales. Digitalización: Darío Albornoz (ISESCONICET). c) Fragmentos incisos y pintados (Sunchituyoj) recolectados en El Veinte en el año 2019.

Figure 5. a) and b) Material recovered in EI Veinte by A. M. Lorandi. Unpublished black and white slides by the author, they do not have scale and the handwritten letters and numbers are original references. Digitization: Darío Albornoz (ISES - CONICET). c) Incised and painted fragments (Sunchituyoj) collected in El Veinte in 2019.

en directo del material. La misma también se muestra semejante a la clasificada como Las Mercedes Antajé por Gómez. Se puede asumir con bastante confianza que en Sayanita apareció en montículos, y que estos y el material en superficie eran apenas visibles debido a

extraña. La temática predominante son los zigzag de línea continua o punteada, reticulados, triángulos rellenos con puntos o líneas simples. En algunos casos pueden tener pintura blanca cubriendo la incisión ${ }^{15}$. Temáticamente se vinculan a los tipos de Córdoba" (Lorandi 2015:139, cursivas nuestras). Asociada a ellos hay cerámica Sunchituyoj Fase Las Lomas; está ausente Averías. Finalmente, la autora reconoce un tipo tricolor de "difícil asignación" (Lorandi 1974). La revisión de las diapositivas de la autora nos ofrece un fragmento con motivos similares a Cortaderas pero de tonalidad inversa, que quizás ejemplifica al de "difícil asignación" (Fig. 5c). En nuestro primer reconocimiento superficial del sitio los incisos fueron eventuales, un poco más frecuentes los pintados Sunchituyoj; la mayoría del material observado era oxidante alisado liso o con barbotina (sensu Lorandi 1974); no se detectaron materiales de pasta negra ni tricolores.

\section{Discusión y conclusiones}

Ahora bien, la comparación estilística de los escasos fragmentos de la "cerámica negra grabada" de Sayanita que Reichlen considerara similar a la recuperada por Righetti en el sitio Las Mercedes, permite sostener esta afirmación, al menos hasta tanto se avance en un análisis

\footnotetext{
${ }^{15}$ Característica observada en el tipo que diferenciamos como Santa Rosa Inciso y registrada en los sitios Santa Rosa y Sunchituyoj (Cfr. Reichlen 1940; Wagner y Wagner 1934: Lam. XVIII).
} afecciones del ambiente. También parece poder aceptarse la afirmación de Reichlen de que la cerámica negra grabada y unos pocos fragmentos pintados en negro y rojo sobre engobe naranja (Cortaderas?) se hallaron juntos y en montículos diferentes a aquellos donde halló cerámica Sunchituyoj y fragmentos asimilables al tipo Córdoba Inciso (y tal vez también Santa Rosa Inciso y Bislín Inciso). Esta es una asociación diferencial que repetiría la conocida para sitios de la zona del río Dulce (Antajé + Cortaderas), de la mesopotamia local (Sunchituyoj + Córdoba Inciso + Santa Rosa Inciso) y de la zona en torno al Salado en el Chaco Santiagueño (Sunchituyoj + Córdoba Inciso + Bislín Inciso + Santa Rosa Inciso + eventualmente algún fragmento Antajé), quedando en suspenso la posibilidad de presencia (y tipo de asociación) de fragmentos con rasgos semejantes a la cerámica Aguada en Sayanita.

Por su parte, las dataciones obtenidas por Togo (2004) en contextos con cerámica negra grabada/incisa semejante a la de Sayanita se extienden entre el 1580 \pm 60 AP para el sitio Villa La Punta Guayacán y $1060 \pm 70$ AP para el sitio La Cañada, con un fechado más distanciado de $700 \pm 70$ AP para La Cañada. Estas muestran un rango cronológico inferior no registrado, al menos por ahora, en la zona en torno al Salado. Sin embargo, dadas las semejanzas señaladas, no podemos descartar la posibilidad de una cronología similar para los contextos de Sayanita. Por otro lado, la perduración de cerámica Las Mercedes hasta el segundo milenio registrada en La 
Cañada también habilita la hipótesis de una cronología más tardía para los contextos con Antajé de Sayanita. A la vez, esto revela una superposición cronológica con las ocupaciones más antiguas hasta ahora datadas en la mesopotamia centro-sud-este (Quimili Paso) y en el Salado (El Veinte), las cuales se asocian a otro tipo de materiales incisos, contextos y modo de instalación. Materiales de dichos tipos fueron registrados también en Sayanita, en montículos aparentemente distintos a los que contenían cerámica negra grabada. Por comparación con los contextos fechados en El Veinte y Quimili Paso, y también por dataciones asociadas a cerámica Córdoba Incisa registrada en Córdoba a partir de ca 1100 AP (González 1964; S. Pastor, com. personal 2017), los otros contextos de Sayanita podrían estimarse en torno al límite entre ambos milenios. La potencial superposición de fechas y rangos de las dataciones señaladas también habilita que los distintos materiales cerámicos registrados en Sayanita, en apariencia en montículos distintos, pudieran ser parcialmente contemporáneos. Por cierto, esto no es más que una problematización de la situación, y estas aproximaciones e hipótesis quedan sujetas a nuevas investigaciones que incluyan, por un lado, el estudio directo de los materiales desde diferentes aproximaciones, controles estratigráficos, de asociación y fechados; y por otro, un análisis integral que permita avanzar en la comprensión de los procesos socioculturales locales y regionales. En este último sentido, el cuadro de situación obtenido muestra el uso -en nuestra área de estudio- de la incisión o el grabado en ciertos patrones estilísticos no registrados en zonas circundantes, así como de otros semejantes a los reportados en el Dulce Superior, Sierras de Guasayán y Sierras Centrales. En menor medida se han detectado ssemejanzas de índole muy general (uso de bandas quebradas y triángulos, rellenos o contorneados de puntos o rayas) con la cerámica incisa/grabada de otros sectores de las tierras bajas argentinas (Arroyo del Medio, Litoral). Su profundización y la consideración de su potencial relevancia en relación a nuestro problema de estudio es parte de nuestra agenda de trabajo.

Por su parte, del análisis integral surge que Sayanita constituye el único y más cercano sitio en torno al Salado conocido hasta ahora para el que se constataría un contexto con cerámica estilísticamente análoga a la clasificada como Las Mercedes. Sería también el único sitio de montículos -no solo en torno al Salado- conocido en asociación a este tipo de cerámica (salvo el fragmento del sitio Bislín considerado Antajé). La pregunta es si este tipo de instalación en montículos pudiera pudiera tener que ver con una diferencia vinculada a una adaptación a la plena llanura a partir de que, justamente hacia fines del primer milenio, el ambiente parece haberse vuelto más húmedo (Iriondo 2006; Taboada 2019). Por otro lado, el caso muestra la gran alteración y escasa visibilidad de esta ocupación debido a la dinámica hídrica y sedimentaria regional, a lo que se suma una posible ocupación posterior sobre el mismo espacio. Esto permite hipotetizar que los factores ambientales y culturales locales y los procesos postdepositacionales fueran responsables de la baja visibilidad, no solo de este caso, sino también del escaso registro asociable al primer milenio en la zona de estudio; tema que habrá que abordar con estudios específicos.

En relación al sitio Bislín, salvo un único fragmento ilustrado por los Wagner potencialmente asimilable a Las Mercedes Antajé, no contamos con ningún otro dato para sostener las referencias que incorporan a Bislín entre los sitios con cerámica Las Mercedes.Tampoco hallamos hasta ahora ningún registro de Las Mercedes Grabado ni de Cortaderas en el sitio Bislín. Por el contrario, cabe destacar las diferencias entre el Bislín Inciso y los distintos tipos de Las Mercedes de Gómez, así como la distinta asociación y distribución que puede inferirse en base a la bibliografía y colecciones. Por su parte, nuestra revisión tampoco muestra que en los otros sitios para los que Bleiler señala la presencia de Bislín Inciso en el Salado (Llajta Mauca, Represas de los Indios y Las Lomadas) y en la mesopotamia (Sunchituyoj) haya registros de cerámica asimilable a la considerada Las Mercedes; en todos ellos hay alfarería Sunchituyoj. En Llajta Mauca y Represa de los Indios también hay Averías, de registro regional general tardío (Lorandi 2015; Taboada 2019). Por ahora, esta última puede ser explicada como resultado de ocupaciones posteriores, ya que no hay datos que permitan sostener que Bislín Inciso perdure hasta momentos tardíos o se asocie estratigráficamente a Averías. De hecho, al menos Llajta Mauca y Represas de los Indios son dos sitios de grandes dimensiones (Wagner y Wagner 1934) que entendemos son el fruto de ocupaciones o reocupaciones de larga data (Taboada 2019).

Por su parte, los datos más modernos y fiables aportados por Lorandi para El Veinte (quizás el mismo sitio que Bislín) permiten sostener la asociación entre Bislín Inciso, Santa Rosa Inciso y Sunchituyoj Fase Las Lomas (Lorandi 1977) a partir de inicios del segundo milenio. También se puede reafirmar la ausencia de los tipos Las Mercedes de Gómez en sus registros y diapositivas del sitio y en nuestra prospección. De todos modos, la eventual presencia de algún fragmento análogo a Las Mercedes resultaría cronológicamente posible. En este sentido, los fechados obtenidos en El Veinte (Lorandi et al. 1977) posicionan a dichos contextos en momentos en que la cerámica Las Mercedes seguiría siendo usada en torno al Dulce según los fechados más tardíos de La Cañada obtenidos por Togo (2007). La presencia en El Veinte de materiales alóctonos, como puntas en materias líticas potencialmente procedentes de las Sierras de Guasayán (Gramajo 1978), una campanilla de metal registrada desde al menos el primer milenio en el área valliserrana (Angiorama y Taboada 2008) y referentes estilísticos asimilados a Aguada (Lorandi 1978), habilitan pensar en procesos de circulación de objetos e ideas, y también de personas, hacia esta época y entre estos espacios (Taboada 2019). A la vez, la estructura de los montículos 
de El Veinte (y de Quimili Paso) nos llevó a proponer que pudiera ser fruto de reocupaciones periódicas, quizás asociadas a cierta movilidad residencial. Esta podría vincularse a factores ambientales, que hacia esa época parecen haber cambiado haciendo la región menos árida y más hospitalaria, generando el desarrollo de un modo de instalación apropiado -como los montículospara una zona inundable (Taboada 2016, 2019). Como sea, no descartamos, sino que nos preguntamos, por la posibilidad de contextos más antiguos que pudieran ser de baja densidad y que, como en el caso de Sayanita, pudieran estar ocultos y manifestarse sutil o eventualmente. De hecho, este último sitio nos muestra que manifestaciones culturales de dicho tipo estuvieron presentes en la región. Más aún, la constatación a futuro de la existencia de montículos en Sayanita y su datación podrían hacer retroceder el registro de los mismos en la zona a algún momento del primer milenio, época en que ya habría empezado el cambio climático a nivel regional (Iriondo 2006).

En síntesis, los sitios hoy conocidos con cerámica Las Mercedes (sensu Gómez 1966 y Reichlen 1940), siguen siendo limitados y espacialmente concentrados a ciertos sectores de SdE: cuenca alta y media-alta del rio Dulce y Sierras de Guasayán, con un único caso en una zona cercana al Salado en el sitio Sayanita. Mientras, queda clara la existencia en el chaco santiagueño y mesopotamia centro-sud de materiales incisos/grabados, contextos y tipo de instalación diferentes a los asociados a cerámica Las Mercedes en el oeste provincial, y que se despliegan allí desde, al menos, fines del primer milenio. Aun cuando las dataciones regionales para el primer milenio coinciden casi totalmente con aquellos sitios con cerámica Las Mercedes y se ubican en el oeste provincial, se aparta de esta situación un fechado de $1140 \pm 60$ AP obtenido por Lorandi en Quimili Paso. Estaría asociado, en principio (no hay datos específicos para este fechado sino referencias generales que incluirían también este contexto), a fragmentos Sunchituyoj y otros pintados, y también a algunos incisos no descriptos, en general "cubiertos con una capa de pintura amarilla" (¿Santa Rosa Inciso Pintado?) (Lorandi 2015:77). Esto abriría la posibilidad de un desarrollo parcialmente coetáneo a la cerámica Las Mercedes dentro del primer milenio.

Por otro lado, las indicaciones de Reichlen sobre el estado de los montículos y materiales de Sayanita nos alertan sobre la degradación, nivelación, ocultamiento y falta de visibilidad de contextos de este tipo en el área. Esto resulta consistente con la dinámica geoambiental, con el aparente cambio climático regional devenido a partir de aproximadamente mediados del primer milenio, con la escasez de registro de evidencias de este tipo, con la ausencia de fechados para esa época en la zona y con los procesos de crecimiento y/o reocupación de ciertos sitios. Es de suponer que el Cálido Medieval y aumento de humedad pudiera haber influido en el escaso registro actual, ya que debió generar un corrimiento de cauces y una alta sedimentación al aumentar el régimen hídrico. Esto pudo degradar ocupaciones previas y nivelar montículos si existían.

De todos modos, aun considerando los posibles procesos postdepositacionales, parece demasiado escaso el único registro de Sayanita para pensar en una ocupación similar regional importante invisibilizada. Al respecto, cabe recordar que una de las motivaciones de las investigaciones de Lorandi era el análisis del Período Temprano y su potencial relación con lo que ocurría con las poblaciones del área valliserrana (Alamito, Ambato) sobre las que había trabajado al iniciar su carrera (Taboada 2017). Esto le confería a la autora un plus de experiencia y motivación en las identificaciones y búsquedas realizadas en SdE. A pesar de ello, Lorandi no ubicó sitios del primer milenio (salvo por el único fechado de Quimili Paso), lo cual sumado al muy escaso registro asignable a tal periodo por parte de los Wagner en sus amplias excavaciones (la documentación nos muestra que, cuando aparecía, dicho material se recolectaba) permite desestimar un potencial sesgo de muestro por desinterés o no identificación, y nos alerta sobre que, a una baja visibilidad por factores postdepositacionales, se agregue una posible real escasez o baja densidad de estos sitios y materiales en la zona de estudio.

En dicho sentido, la identificación de una gradación espacial de oeste a este de los fechados más tempranos obtenidos regionalmente introduce un nuevo elemento para analizar a futuro. Habrá que considerar si tal situación puede ser resultado de un sesgo de muestreo, o podría estar reflejando un proceso de instalación o circulación diferencial entre las sierras y la llanura santiagueña para la época de estudio, quizás menos permanente o densa en esta última por las cuestiones ambientales y modo de vida estimados precedentemente. En este sentido, resulta sugerente que los registros más antiguos de montículos hasta ahora conocidos en la Provincia se dan en plena llanura y corresponden a ocupaciones datadas a partir de fines del primer milenio (Taboada 2019). Los cambios ambientales pudieron ser así la causa que habilitó en dicha época una mayor densidad o estabilidad de ocupación en dicha área, y la necesidad de innovar con la instalación en montículos, aparentemente inexistentes en la zona del Dulce superior y Sierras de Guasayán en momentos previos y coetáneos. Nos resta analizar, por su parte, si por entonces hubo dinámicas socioculturales vinculadas a las devenidas en el Chaco y Litoral, como parecen darse posteriormente (Taboada 2019).

Finalmente caben algunas acotaciones sobre las clasificaciones y tipos cerámicos. Parece claro que hay un problema a la hora de definir, identificar, diferenciar y considerar los grupos cerámicos originalmente propuestos como Las Mercedes y otros tipos incisos o grabados de la literatura regional, como el Bislín Inciso y 
el Córdoba Inciso. Cabe concluir que hay una diversidad de incisos y grabados que incluyen pastas negras, grises, beiges, marrones y rojas. En suma, la cerámica incisa/ grabada, negra o de otros colores de pasta hallada en SdE requiere dejar de ser clasificada o asumida a priori como Las Mercedes y referente de un periodo Temprano y una entidad sociocultural de caracteres comunes y distribuida en toda la Provincia, para empezar a ser estudiada particularmente y en relación a cada contexto donde se la encuentra. Visualizados los problemas de las clasificaciones y nomenclaturas existentes, y con hipótesis sobre las posibles causas de una casi total ausencia de identificación de registros para momentos previos al límite entre el primer y segundo milenio en torno al Salado, nuestra agenda se dirige ahora al diseño de una metodología para abordar los distintos aspectos necesarios de profundizar señalados previamente.

Yerba Buena, noviembre de 2019.

\section{Agradecimientos}

Agradecemos a Cristina Campitelli y a Alejandro Yocca por las autorizaciones para estudiar materiales del CCB y del CICPSE, a Analía Sbatella y al personal de la Dirección de Patrimonio de Santiago del Estero por su colaboración en dichas tareas; a José Galván por las fotografías de las piezas, a Ernesto Rodríguez Lascano por la confección del mapa; a los organizadores del Dossier por la invitación a participar del mismo. La investigación fue financiada por los proyectos PIP 156, PIUNT 604 y PUE 0093.

\section{Bibliografía}

Angiorama, C. y Taboada, C. (2008). Metales andinos en la llanura santiagueña (Argentina). Revista Andina, (4), 117-150.

Bleiler, E. (1948). The East. En W. Bennett, B. Bleiler, y F. Sommer (Eds.), Northwest Argentine Archaeology, University Publications in Anthropology 38 (pp. 120-139). New Haven, Estados Unidos: Yale.

Cione, A., Lorandi, A. M. y Tonni, E. (1979). Patrón de subsistencia y adaptación ecológica en "El Veinte" (Santiago del Estero). Relaciones, (13), 103-116.

Del Papa, L. (2012). Una aproximación al estudio de los sistemas de subsistencias a través del análisis arqueofaunístico en un sector de la cuenca del Río Dulce y cercanías a la Sierra de Guasayán [Tesis Doctoral inédita, Facultad de Ciencias Naturales y Museo, Universidad Nacional de La Plata].

Del Papa, L. y De Santis, L. (2015). No se les escapó la tortuga. Uso antrópico de Chelonoidis chilensis en un sitio de la región Chaco-Santiagueña (provincia de Santiago del Estero). Arqueología, 21 (1), 115-135.
Flores, P., Pérez Pieroni, M., López Campeny, S. y Taboada, C. (2019). Torteros, tecnología e identidad. Primeras aproximaciones submacroscópicas a la pasta cerámica de instrumental textil de la llanura santiagueña. Libro de resúmenes del XX Congreso Nacional de Arqueología Argentina. Córdoba, Argentina.

Gómez, R. (1966). La Cultura de Las Mercedes (Contribución a su estudio). Santiago del Estero, Argentina.

Gómez, R. (2009) [1976]. Arqueología santiagueña: un diseño de investigación para el Formativo Inferior. Fase explorativa. Revista del Museo de Antropología, 2(1), 53-66.

González, A. R. (1964). Nuevas fechas de la cronología arqueológica argentina obtenidas por el método del radiocarbono (V). Revista del Instituto de Antropología, (2-3), 289-297.

González, A. R. (1977). Arte precolombino de la Argentina. Introducción a su Historia Cultural. Buenos Aires, Argentina: Filmediciones Valero.

Gramajo, A. (1978). Evolución cultural en el territorio santiagueño a través de la arqueología. Serie Monográfica, (5), 3-39.

Imbelloni, J. (1940). Síntesis antropológica. Relaciones, (2), 79-121.

Iriondo, M. (2006). Cambios ambientales en el Chaco argentino y boliviano en los últimos miles de años. Folia Histórica del Nordeste, (16), 39-49.

Kraglievich, L. y Rusconi, C. (1934). Restos de vertebrados vivientes y extinguidos hallados por los señores E. R. Wagner y hermano en túmulos precolombinos de Santiago del Estero. La Civilización Chaco-Santiagueña y sus correlaciones con las del Viejo y Nuevo Mundo (apéndice). Buenos Aires, Argentina: Compañía Impresora Argentina.

Lindskoug, H. B. (2012). Jorge von Hauenschild. Collections 8, (2), 127.

Lorandi, A. M. (1974). Espacio y tiempo en la prehistoria santiagueña. Relaciones, VIII, 199-236.

Lorandi, A. M. (1977). Significación de la Fase Las Lomas en el desarrollo cultural de Santiago del Estero. Relaciones, $\mathrm{XI}$, 69-78.

Lorandi, A. M. (1978). El desarrollo cultural prehispánico en Santiago del Estero, Argentina. Journal de la Société des Amèricanistes, LXV, 61-85. 
Lorandi, A. M. (2015). Tukuma-Tukuymanta. Los pueblos del búho. Santiago del Estero antes de la Conquista. Santiago del Estero, Argentina: Subsecretaría de Cultura.

Lorandi, A. M., Arias, R., Gonaldi, M., Mulvany, E, y Nordio, L. (1977). La Fase Las Lomas de la tradición cultural Chaco Santiagueña. Etnía, (31), 1-12.

Martínez, A., Taboada, C. y Auat, A. (2011). Los hermanos Wagner: entre ciencia, mito y poesía. Arqueología, campo arqueológico nacional y construcción de identidad en Santiago del Estero (1920-1940). Santiago del Estero, Argentina: Editorial UNQ.

Oliva, M. G. (1947). Contribución al estudio de la arqueología del norte de la Provincia de Córdoba: los paraderos de Pozo de las Ollas y Laguna de la Sal (No. 16). Córdoba, Argentina: Imprenta de la Universidad.

Pautassi, E., Conte, B., Brizuela, C., Brancolini Pedetti, O., Mignino, J. y Bigi, L. (2017). Conservación, digitalización y documentación de la colección Von Hauenschild, reserva patrimonial del Museo de Antropología (FFyH-UNC). Cuadernos del Instituto Nacional de Antropología y Pensamiento Latinoamericano-Series Especiales, 5(2), 46-54.

Reichlen, H. (1940). Recherches Archéologiques dans la Province de Santiago del Estero (Rép. Argentine). Journal de la Societé des Amèricanistes, LXV, 133-225. Traducción inédita de Ana Teresa Martínez. PICT 25570.

Serrano, A. (1958). Manual de Cerámica Indígena. Córdoba, Argentina: Assandri.

Taboada, C. (2011). Repensando la Arqueología de Santiago del Estero. Construcción y análisis de una problemática. Relaciones, (36), 197-219.

Taboada, C. (2014). Sequía Vieja y los bañados de Añatuya en Santiago del Estero: Nodo de desarrollo local e interacción macrorregional. Comechingonia Virtual:
Revista Electrónica de Arqueología, 18(1), 93-116.

Taboada, C. (2016). Montículos arqueológicos, actividades y modos de habitar. Vivienda y uso del espacio doméstico en Santiago del Estero (tierras bajas de Argentina). Arqueología de la Arquitectura, (13), http://arqarqt. revistas.csic.es/index.php/arqarqt/article/view/195/270.

Taboada, C. (2017). Ana María Lorandi y el inicio de la arqueología moderna para Santiago del Estero: reconstrucción de un campo de estudio y preludio de una perspectiva. Surandino Monográfico, (3), 18-35.

Taboada, C., López Campeny, S. y Angiorama, C. (2018). Una placa de metal y un tejido de algodón: implicancias en relación a procesos locales, incaicos y coloniales en la llanura de Santiago del Estero (Argentina). Estudios Atacameños, 59, 121-154.

Taboada, C. (2019). Procesos sociales prehispánicos y pericoloniales en torno a los ríos Salado y Dulce (Santiago del Estero, Argentina). Revista del Museo de La Plata, $4(2), 511-540$.

Togo, J. (2004). Arqueología Santiagueña: Estado actual del conocimiento y evaluación de un sector de la cuenca del Río Dulce. [Tesis Doctoral inédita. Universidad Nacional de La Plata].

Togo, J. (2007). Los primeros fechados radiocarbónicos de Las Mercedes. Indoamérica, I (1), 51-80.

Von Hauenschild, J. (1949). Ensayo de clasificación de la documentación arqueológica de Santiago del Estero. Revista de la Universidad Nacional de Córdoba, XXXVI, 7-75.

Wagner, E. y Wagner, D. (1934). La Civilización ChacoSantiagueña y sus correlaciones con las del Viejo y Nuevo Mundo 1. Buenos Aires, Argentina: Compañía Impresora Argentina. 